\title{
FEMORAL INSERTION OF THE POSTERIOR CRUCIATE LIGAMENT: AN ANATOMICAL STUDY
}

Ricardo de Paula Leite Cury ${ }^{1}$, Nilson Roberto Severino², Osmar Pedro Arbix Camargo ${ }^{3}$, Tatsuo Aihara ${ }^{4}$, Leopoldo Viana Batista Neto ${ }^{5}$, Dedley Nelson Goarayeb ${ }^{5}$

\section{ABSTRACT}

Objective: To identify objective parameters to guide correct location of the posterior cruciate ligament (PCL) in the femur. Methods: The PCLs of 20 human cadavers were resected. The following portions were measured: distance from the most distal portion of the PCL, close to the roof, to the most anterior edge of the cartilage (AB); distance from the most proximal portion of the PCL, close to the roof, to the most anterior cartilage (AC); distance between the two parts of the ligament close to the roof $(\mathrm{BC})$; distance from the distal edge in its posterior portion, to the more posterior joint edge (DE); distance from the distal edge of the ligament in its posterior portion, to the intercondylar roof (DF); and finally, the format of the ligament insertion and area of coverage on the femoral condyle. Results: The PCL has the shape of a quarter ellipse, with an average area of $153.5 \mathrm{~mm}^{2}$. The mean distances found were: $\mathrm{AB}$ of $2.1 \mathrm{~mm}, \mathrm{AC}$ of $10.7 \mathrm{~mm}, \mathrm{BC}$ of $8.6 \mathrm{~mm} \mathrm{DE}$ of $12.4 \mathrm{~mm}$ and DF of $16.8 \mathrm{~mm}$. Conclusions: The edge close to the roof of the anterolateral bundle is closer to the joint cartilage $(2.1 \mathrm{~mm})$ than the posteromedial bundle is, which is $12.4 \mathrm{~mm}$ from the edge proximal to the cartilage. These references should assist in better and more accurate positioning of femoral tunnels in PCL reconstruction.

Keywords - Posterior Cruciate Ligament/anatomy \& histology; Knee; Dissection; Knee Injuries

\section{INTRODUCTION}

Studies have shown that the posterior cruciate ligament (PCL) is the main stabilizer for posterior tibial translation and the secondary stabilizer for containment of varus, valgus and external rotation ${ }^{(1-3)}$. These functions are performed by its two bundles: the anterolateral bundle, which is tense between 70 and 90 degrees, and the posteromedial bundle, which is tense at almost complete extension. Biomechanical studies have demonstrated that surgical reconstruction with two bundles is superior to simple reconstruction ${ }^{(4-9)}$, although these results have not been demonstrated in all studies on humans ${ }^{(10-12)}$. Poor tunnel positioning in PCL reconstruction has been identified as one cause of failure in reconstructing this ligament. However, errors in femoral positioning have a greater impact on the final stability than does poor tibial positioning ${ }^{(13)}$. The present anatomical study had the aim of providing objective parameters for guiding correct positioning of the PCL on the femur.

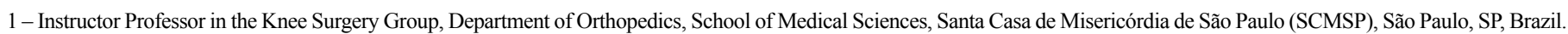

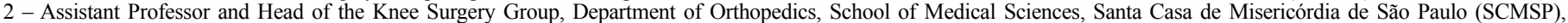
São Paulo, SP, Brazil.

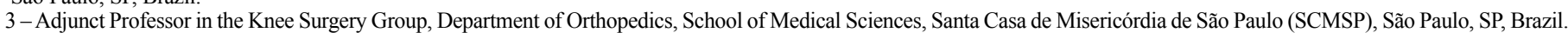

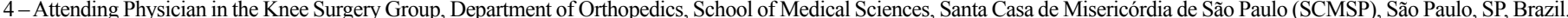

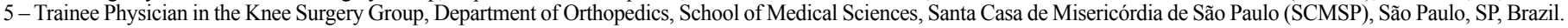

Work performed in the Department of Orthopedics, School of Medical Sciences, Santa Casa de Misericórdia de São Paulo (SCMSP).

Correspondence: Rua Barata Ribeiro 380, cj. 66, Bela Vista, 01308-000 São Paulo, SP, Brazil. E-mail: contato@drricardocury.com.br

Work received for publication: July 20, 2010; accepted for publication: February 16, 2011. 


\section{METHODS}

Twenty knees from fresh cadavers (14 from males) were used in this study. The age range was from 13 to 84 years, with a mean of 56.3 years. Twelve right knees and eight left knees were dissected.

An anterior medial incision was made in the knee, including the skin and subcutaneous tissue, followed by sectioning of the patellar ligament and moving the extensor mechanism anteriorly in order to view the joint. Next, using an oscillating saw, the lateral femoral condyle was osteotomized in an inverted "L" shape, to achieve complete viewing of the insertion of the PCL in the femur (medial femoral condyle). The PCL was then partially resected, while keeping part of the ligament inserted in the condyle so that the study variables could be adequately assessed.

The most proximal and distal portions of the ligament against the roof, the posterior portion of the most distal extremity and the apex of the parabola formed by the ligament close to the edge of the joint cartilage were marked out. The images were digitized and analyzed using the AutoCAD software (Autodesk, 2006 version), which made it possible to define and determine the image format and the distances and coverage areas to be measured (Figure 1). Using this software, a line was traced out on the intercondylar roof and, by means of this link and the repair points that had been inserted during the dissection, some points on the ligament were defined: point " $\mathrm{B}$ " was the most distal edge of the cruciate ligament close to the roof; point "C" was the most proximal edge of the ligament close to the roof; point " $\mathrm{D}$ " was the proximal edge of the ligament in its posterior portion; and point "F" was the distance established from a section marked out by a line from point " $\mathrm{D}$ " to the perpendicular passage point on the intercondylar roof (Figure 2).

By joining $\mathrm{B}, \mathrm{C}$ and $\mathrm{D}$, the ligament format could be determined. Through defining a line segment between points $\mathrm{B}$ and $\mathrm{C}$, another segment between $\mathrm{D}$ and $\mathrm{C}$ and a parabola from $\mathrm{D}$ to $\mathrm{B}$, a shape of a quarter ellipse was obtained. From this shape, the insertion area of the ligament in the lateral part of the medial femoral condyle could be calculated (Figure 3 ).

Point A was determined by tracing out a line from points $\mathrm{B}$ and $\mathrm{C}$, parallel to the diaphysis, to the most anterior edge of the joint cartilage of the medial condyle. Point $\mathrm{E}$ was determined by a line through D, parallel to the diaphysis, extending to the edge of the cartilage.
Points A and $\mathrm{E}$ were the references used for measuring the distances from the ligament to the edge of the cartilage.

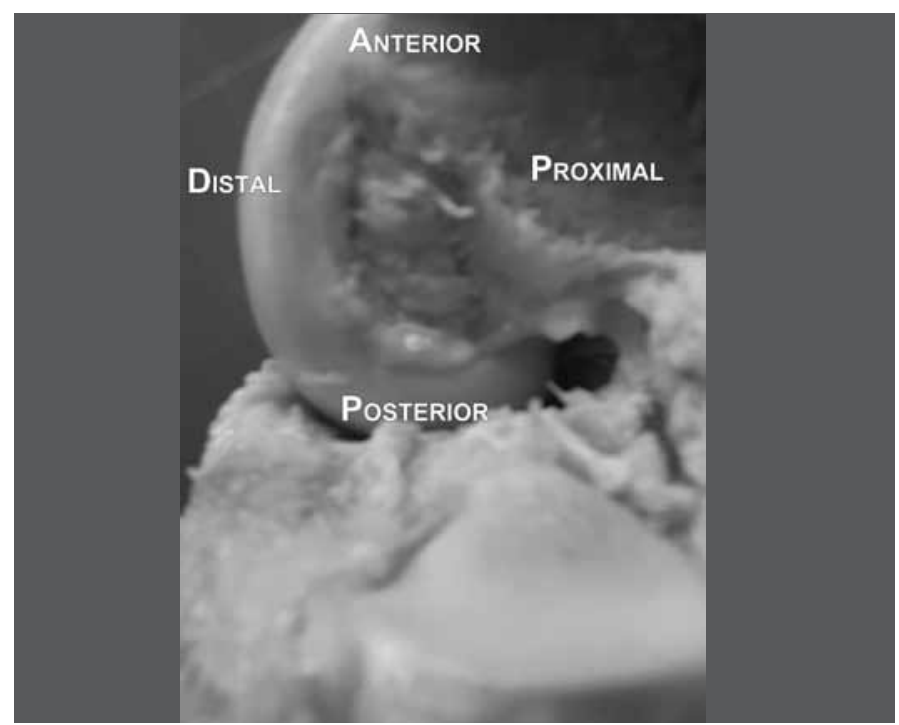

Figure 1 - Partial resection of the posterior cruciate ligament and its femoral insertion.

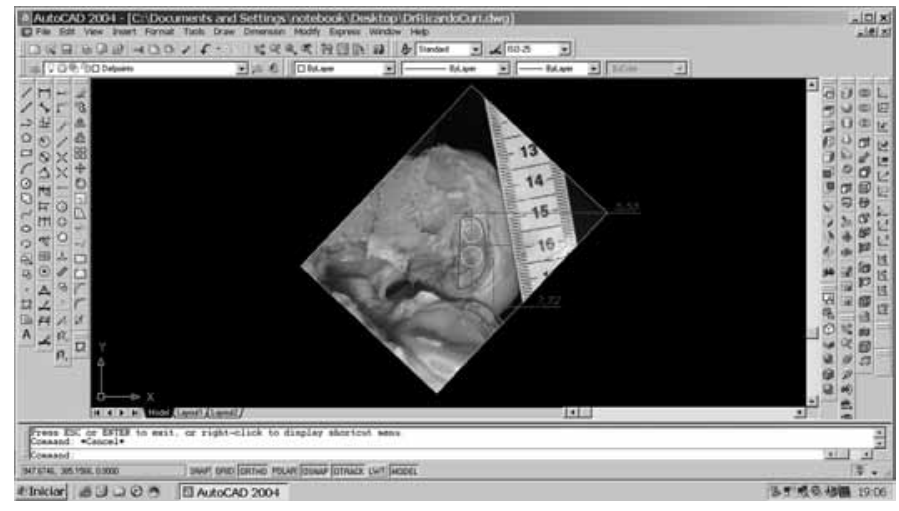

Figure 2 - Measurements from the AutoCAD 2006 software.

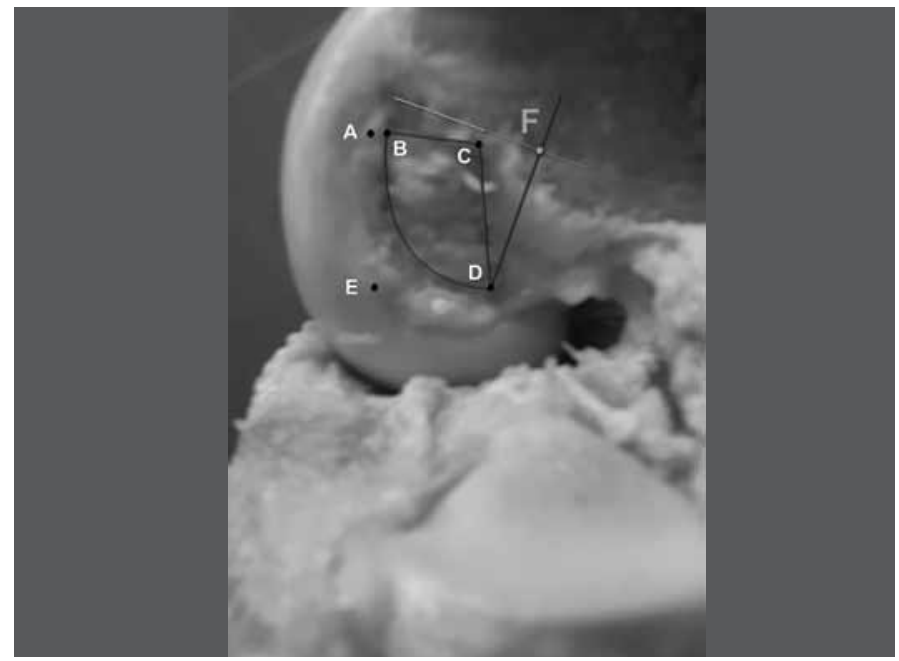

Figure 3 - Marking of points at the femoral insertion of the posterior cruciate ligament from the AutoCAD 2006 software measurements. 
The distances between the following points were measured:

Distance A-B: the most distal portion of the ligament, close to the roof, to the edge of the anterior cartilage;

Distance A-C: the most proximal portion of the ligament, close to the roof, to the edge of the anterior cartilage;

Distance B-C: between the two portions of the cruciate ligament, close to the roof;

Distance D-E: from the proximal edge of the posterior portion of the ligament to the most posterior edge of the joint;

Distance D-F: from the distal extremity of the posterior portion of the ligament to the intercondylar roof.

All of these distances were measured by taking a line parallel to the diaphysis as the standard. All the values were expressed in millimeters and were recorded in a table. The mean values between the points and the mean extent of the ligament at its insertion site in the condyle were calculated. The $95 \%$ confidence interval was calculated.

\section{RESULTS}

All the ligaments had two bands (anterolateral and posteromedial) and were in the shape of a quarter ellipse, varying only in their size (Table 1).

The coverage areas ranged from 89.5 to $248.5 \mathrm{~mm} 2$, with a mean of $153.5 \mathrm{~mm} 2$. For the distances from the ligament to the joint cartilage, the following values were obtained:

Table 1 - Distance between the ligament and the joint cartilage, based on the standard points.

\begin{tabular}{|c|c|c|c|c|c|c|}
\hline \multirow{2}{*}{ Distance } & \multirow{2}{*}{ Mean } & \multirow{2}{*}{$\begin{array}{l}\text { Standard } \\
\text { deviation }\end{array}$} & \multirow{2}{*}{$\begin{array}{l}\text { Mini- } \\
\text { mum }\end{array}$} & \multirow{2}{*}{$\begin{array}{l}\text { Maxi- } \\
\text { mum }\end{array}$} & \multicolumn{2}{|c|}{$\begin{array}{c}\text { Confidence } \\
\text { interval }\end{array}$} \\
\hline & & & & & $\begin{array}{l}\text { Lower } \\
\text { limit }\end{array}$ & $\begin{array}{l}\text { Upper } \\
\text { limit }\end{array}$ \\
\hline $\mathrm{BC}$ & 8.6 & 1.9 & 6.3 & 12.2 & 7.6 & 9.5 \\
\hline$A B$ & 2.1 & 0.8 & 0.8 & 3.2 & 1.7 & 2.5 \\
\hline$A C$ & 10.7 & 2.0 & 7.8 & 14.6 & 9.7 & 11.6 \\
\hline $\mathrm{DE}$ & 12.4 & 4.3 & 6.4 & 20.1 & 10.2 & 14.5 \\
\hline DF & 16.8 & 4.7 & 9.5 & 26.9 & 14.5 & 19.2 \\
\hline
\end{tabular}

Distance A-B: mean of $2.1 \mathrm{~mm}$, ranging from 0.8 to $3.2 \mathrm{~mm}$; Distance A-C: mean of $10.7 \mathrm{~mm}$, ranging from 7.8 to $14.6 \mathrm{~mm}$; Distance B-C: mean of $8.6 \mathrm{~mm}$, ranging from 6.3 to $12.2 \mathrm{~mm}$; Distance D-E: mean of $12.4 \mathrm{~mm}$, ranging from 6.4 to $20.1 \mathrm{~mm}$; Distance D-F: mean of $16.8 \mathrm{~mm}$, ranging from 9.5 to $26.4 \mathrm{~mm}$.

\section{DISCUSSION}

New techniques for knee ligament reconstruction, such as inlay reconstruction or use of two bundles in the femur, have arisen with the aim of improving the clinical results. In relation to the PCL, anatomical and biomechanical studies have been of great importance for better understanding and refinement of the results $^{(4-6,14,15)}$.

According to the review by Van Dommelen and Fowler ${ }^{(1)}$, the PCL is located close to the rotation axis and slightly medially to the center of the knee, with insertion in the lateral portion of the medial femoral condyle. Mejia et $a l^{(16)}$ compared the intercondylar sulcus with the hands of a clock and concluded that the PCL would be in a position between 12 o'clock and four o'clock on the right knee and between 12 o'clock and eight o'clock on the left knee. Harner et $a l^{(17)}$ investigated the transsection area of the cruciate ligaments in five human cadavers, with evaluation of the ligament substance and its insertion sites in the femur and tibia, and concluded that the femoral insertion of the PCL is relatively planar, with a half-moon shape and a separation line between the anterolateral and posteromedial lines, going from proximal to distal. Girgis et $a l^{(18)}$ concluded that the PCL had a horizontal semicircular shape at its insertion site in the femur. However, other authors like Inderster et $a l^{(19)}$ discovered that the femoral origin of the PCL had different shapes (ellipse, half-ellipse and partial ellipse) and that its largest diameter always had a dorsoventral orientation. Mejia et $a l^{(16)}$ also did not find any single pattern in their dissections: although the elliptical format was most frequent, an oval pattern was observed in some knees, as described by Lopes et $a l^{(20)}$ in 20 knees, of which 15 had a semicircular shape and five were oval. In our study, we found the quarter-ellipse shape in all cases, with variation only regarding the dimensions. We believe that the variations in the above descriptions, despite the precision of the methods used for gathering and analyzing the anatomical data, were also due to the authors' judgments, involving interpretations and subjective issues.

Girgis et $a l^{(18)}$ studied the knees of 24 fresh cadavers and 20 patients. They concluded that the mean length of the PCL was $38 \mathrm{~mm}$ and the mean diameter was $13 \mathrm{~mm}$. In addition, they observed that the femoral insertion was $32 \mathrm{~mm}$ in length at its greatest diameter. 
Inderster et $a l^{(19)}$ concluded that the dorsoventral and proximal-distal diameters at the femoral origin of the PCL were 20.9 and $12.2 \mathrm{~mm}$, respectively.

Harner et $a l^{(3)}$ evaluated the femoral insertion of the PCL in eight human cadavers and concluded that it was $500 \%$ bigger than the intrasubstance transsection insertion area. These authors evaluated five knees from fresh cadavers and observed that the femoral insertion area of the PCL was, on average, three times bigger than the area at the level of the ligament substance, with variation of $128 \pm 22 \mathrm{~mm}^{2}$. They also determined the length of each bundle at the level of the femur, and discovered that each component occupied approximately $50 \%$ of the PCL insertion, but that the transverse area of the anterolateral bundle was twice the size of that of the posteromedial bundle. This information was not investigated in our study, but the total area observed in our cases was $153.5 \mathrm{~mm} 2$. In turn, Lopes et al (20) described an even bigger area, of $209 \mathrm{~mm} 2$, with 118 $\mathrm{mm} 2$ for the anterolateral bundle and $90 \mathrm{~mm} 2$ for the posteromedial bundle. They believed that the difference found in their study, in comparison with the literature, was due to the three-dimensional evaluation method that was used, and also to inclusion of all the peripheral fibers of the PCL in the measurement. The data show that the PCL has a large insertion area, and that perhaps there is a need for thicker grafts or for more than one graft in the ligament reconstruction. The PCL does not have isometric behavior, i.e. simple reconstruction at the so-called isometric point does not restore stability to the posterior region of the knee, and anatomical reconstruction of the ligament is necessary. Thus, the anatomical positioning of the bundles in tunnel reconstruction has been described as one of the main factors determining the degree of success of ligament reconstruction $^{(13,21)}$.

Mejia et $a l^{(16)}$ evaluated 12 non-paired knees from human cadavers and described four ways of measuring the distance between the PCL and the edge of the cartilage, by means of lines perpendicular to the cartilage, lines parallel to the femoral diaphysis, lines parallel to the intercondylar roof and lines radial to the joint cartilage. They concluded that the greatest precision was achieved through evaluation using lines parallel to the diaphysis and lines perpendicular to the cartilage. In the first measurement, they found a distance of $2.38 \mathrm{~mm}$ from the distal extremity of the PCL and $13.75 \mathrm{~mm}$ from the part proximal to the joint cartilage in the same one o'clock position. The thickness in this region was $11.38 \mathrm{~mm}$. At the four o'clock position, the distances were $3.78 \mathrm{~mm}$ to the distal part, $11.06 \mathrm{~mm}$ to the proximal part between the PCL and the joint cartilage, and $7.39 \mathrm{~mm}$ for the ligament thickness. In our study, we evaluated the relationship between the PCL and the joint cartilage by means of lines parallel to the femoral diaphysis, because of the precision of this method and because we believe that during ligament reconstruction, the femoral diaphysis is a practical reference point that is easy to see. Our results are also consistent with those of Mejia et al ${ }^{(16)}$. In our study, the mean distance from the most distal portion of the ligament, close to the roof (anterolateral bundle), to the most anterior edge of the joint cartilage (distance $\mathrm{AB}$ ), was $2.1 \mathrm{~mm}$, with a range from $0.8 \mathrm{~mm}$ to $3.2 \mathrm{~mm}$. For the posteromedial bundle, the mean distance from the proximal edge of the posterior portion of the ligament to the most posterior portion of the joint cartilage was $12.4 \mathrm{~mm}$, with a range from $6.4 \mathrm{~mm}$ to $20.1 \mathrm{~mm}$, which was similar to the $11.06 \mathrm{~mm}$ for the proximal part of the PCL at four o'clock, described by Mejia et al ${ }^{(16)}$. Lopes et $a l^{(20)}$ described a prominence in the bone proximal to the insertion of the PCL, which they called the intercondylar medial ridge. This bone prominence was present in 18 of the 20 knees dissected and corresponded to the proximal limit of the PCL. Its distance from the joint cartilage was $11.63 \mathrm{~mm}$, which was similar to the $12.4 \mathrm{~mm}$ found in our study. Lopes et $a l^{(20)}$ also measured the distance from the center of the anterolateral and posteromedial bundles to the joint cartilage, and found that these distances were $7 \pm 11.02 \mathrm{~mm}$ and $8 \pm 0.99 \mathrm{~mm}$. Because of the shape of the insertion (a quarter ellipse in our study), and even with the possibility of isolating the two bundles of the PCL, correct assessment of the center of each bundle was questionable and hence locating it was somewhat subjective. Thus, we based our assessment on the peripheral limits of the ligament, as described above.

\section{CONCLUSION}

The insertion of the PCL in the femur took the shape of a quarter ellipse covering an area of $153.5 \mathrm{~mm} 2$. The proximal edge of the roof of the anterolateral bundle was closer to the joint cartilage $(2.1 \mathrm{~mm})$ than was the proximal edge of the posteromedial bundle $(12.4 \mathrm{~mm})$. Because of the nature of anatomical reconstruction of the PCL, we believe that these reference points may contribute towards better and more precise positioning of femoral tunnels. 


\section{REFERENCES}

1. Van Dommelen BA, Fowler PJ. Anatomy of the posterior cruciate ligament. A review. Am J Sports Med. 1989;17(1):24-9.

2. Covey DC, Sapega AA. Anatomy and function of the posterior cruciate ligament. Clin Sports Med. 1994;13(3):509-18.

3. Harner CD, Xerogeanes JW, Livesay GA, Carlin GJ, Smith BA, Kusayama $\mathrm{T}$, et al. The human posterior cruciate ligament complex: an interdisciplinary study. Ligament morphology and biomechanical evaluation. Am J Sports Med. 1995;23(6):736-45.

4. Race A, Amis AA. PCL reconstruction. In vitro biomechanical comparison of "isometric" versus single and double-bundle 'anatomic' grafts. J Bone Joint Surg Br. 1998;80(1):173-9.

5. Harner CD, Janaushek MA, Kanamori A, Yagi M, Vogrin TM, Woo SL. Biomechanical analysis of a double-bundle posterior cruciate ligament reconstruction. Am J Sports Med. 2000;28(2):144-51.

6. Mannor DA, Shearn JT, Grood ES, Noyes FR, Levy MS. Two-bundle posterior cruciate ligament reconstruction. An in vitro analysis of graft placement and tension. Am J Sports Med. 2000;28(6):833-45.

7. Valdevit A, Kambic H, Lilly D, Graham S, Parker R, Bergfeld J. Non-linea fitting of mechanical data for efficacy determination of single versus double bundle Achilles tendon grafts for PCL reconstructions. Biomed Mater Eng. 2002;12(3):309-17.

8. Shearn JT, Grood ES, Noyes FR, Levy MS. Two-bundle posterior cruciate ligament reconstruction: how bundle tension depends on femoral placement. J Bone Joint Surg Am. 2004;86(6):1262-70.

9. Markolf KL, Feeley BT, Jackson SR, McAllister DR. Biomechanical studies of double-bundle posterior cruciate ligament reconstructions. J Bone Joint Surg Am. 2006;88(8):1788-94.

10. Wang CJ, Weng LH, Hsu CC, Chan YS. Arthroscopic single - versus doublebundle posterior cruciate ligament reconstructions using hamstring autograft Injury. 2004;35(12):1293-9.
11. Hatayama K, Higuchi H, Kimura M, Kobayashi $\mathrm{Y}$, Asagumo H, Takagishi K. A comparison of arthroscopic single - and double-bundle posterior cruciate ligament reconstruction: review of 20 cases. Am J Orthop. 2006;35(12):568-71.

12. Fanelli GC, Edson CJ, Reinheimer KN, Garofalo R. Posterior cruciate ligament and posterolateral corner reconstruction. Sports Med Arthrosc. 2007;15(4):168-75.

13. Galloway MT, Grood ES, Mehalik JN, Levy M, Saddler SC, Noyes FR. Posterior cruciate ligament reconstruction. An in vitro study of femoral and tibial graft placement. Am J Sports Med. 1996;24(4):437-45.

14. Whiddon DR, Zehms CT, Miller MD, Quinby JS, Montgomery SL, Sekiya JK. Double compared with single-bundle open inlay posterior cruciate ligament reconstruction in a cadaver model. J Bone Joint Surg Am. 2008;90(9):1820-9.

15. Berg EE. Posterior cruciate ligament tibial inlay reconstruction. Arthroscopy. 1995;11(1):69-76.

16. Mejia EA, Noyes FR, Grood ES. Posterior cruciate ligament femoral insertion site characteristics. Importance for reconstructive procedures. Am J Sports Med. 2002;30(5):643-51

17. Harner CD, Baek GH, Vogrin TM, Carlin GJ, Kashiwaguchi S, Woo SL. Quantitative analysis of human cruciate ligament insertions. Arthroscopy. 1999;15(7):741-9.

18. Girgis FG, Marshall JL, Monajem A. The cruciate ligaments of the knee joint. Anatomical, functional and experimental analysis. Clin Orthop Relat Res. 1975;(106):216-31

19. Inderster A, Benedetto KP, Klestil T, Künzel KH, Gaber O. Fiber orientation of posterior cruciate ligament: an experimental morphological and functional study, Part 2. Clin Anat. 1995;8(5):315-22.

20. Lopes OV Jr, Ferretti M, Shen W, Ekdahl M, Smolinski P, Fu FH. Topography of the femoral attachment of the posterior cruciate ligament. J Bone Joint Surg Am. 2008;90(2):249-55.

21. Covey DC, Sapega AA, Sherman GM. Testing for isometry during reconstruction of the posterior cruciate ligament. Anatomic and biomechanical considerations. Am J Sports Med. 1996;24(6):740-6. 